\title{
Compact MIMO antenna using dual-band for fifth-generation mobile communication system
}

\author{
Debani Prasad Mishra ${ }^{1}$, Kshirod Kumar Rout ${ }^{2}$, Surender Reddy Salkuti ${ }^{3}$ \\ ${ }^{1,2}$ Department of Electrical Engineering, International Institute of Information Technology (IIIT) Bhubaneswar, \\ Odisha, India \\ ${ }^{3}$ Department of Railroad and Electrical Engineering, Woosong University, Daejeon, Republic of Korea
}

\begin{tabular}{l} 
Article Info \\
\hline Article history: \\
Received Jan 24, 2021 \\
Revised Sep 4, 2021 \\
Accepted Sep 9, 2021 \\
\hline
\end{tabular}

\section{Keywords:}

5G communication

CST microwave studio

Dual-band antenna

Impedance matching

MIMO antenna

Smartphones

\begin{abstract}
This paper presents the design of a multiple-input and multiple-output (MIMO) antenna for a fifth-generation (5G) smartphone that will work in dual-band. The antenna proposed in this work operates at 2 frequency ranges, i.e., (3300-3600) MHz and (4800-5000) MHz. The antenna design consists of four antennas that are placed perpendicular to the edge of the system and this makes it different from the traditional $5 \mathrm{G}$ antennas. The area of each antenna on the side frames is $(3.9 \times 17 \mathrm{~mm})$, and hence can be used in ultra-thin smartphones for $5 \mathrm{G}$ applications. The reflection coefficient obtained in the simulations is less than $-6 \mathrm{~dB}$ for the required band, which suggests that the required impedance matching is obtained. The antenna proposed is designed by using central time zone (CST) microwave studio.
\end{abstract}

This is an open access article under the CC BY-SA license.

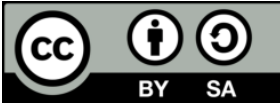

Corresponding Author:

Surender Reddy Salkuti

Department of Railroad and Electrical Engineering

Woosong University

17-2, Jayang-Dong, Dong-Gu, Daejeon-34606, Republic of Korea

Email: surender@wsu.ac.kr

\section{INTRODUCTION}

The popularity of mobile communication networks has increased rapidly within the last few years. Initially, it was used to support communication via calls and texts, but over time, now data transmission is also possible. With the introduction of a new generation, the data rate is increasing and there is also the addition of more features. The previous generations were designed keeping in mind the need for high data rates to be used by few devices simultaneously, but with the introduction of machine-to-machine (M2M) communication, many small devices are becoming an important part of the network [1]. Hence, the $5^{\text {th }}$ generation is expected to be more reliable, to have more data rate that is at least $1 \mathrm{Gbps}$, should not have latency and along with this it should be able to address the above problem as well, that is allowing M2M communication [2].

With the development of modern $5 \mathrm{G}$ wireless communication systems, the user's demand for high speed has also increased tremendously. So, to meet this increasing demand, the research and development of the fifth-generation (5G) antenna are being carried out [3], [4]. In reference [5], 4G/5G multi-antenna that can be used in smartphones in the range of (3400-3600) $\mathrm{MHz}$ was proposed. Again, radio access technologies have also developed to a large extent in recent years due to which diverse types of networks are being merged with wireless communication networks. This has led to the rise of mobile terminals with multi-mode in the field of wireless communication. 5G antenna, multiband antenna, multi-mode antenna, and smart antennas are the antennas whose demands have increased rapidly because they can be used in these terminals [6], [7]. 
Miniaturization of antenna and use of array antennas can lead to high-speed data transmission. Due to this among all these antennas, the one that is especially employed in smartphones is multiple input multiple output that is a multiple-input and multiple-output (MIMO) antenna [8]. This means that a large number of antennas can be placed within the mobile phone's limited space. But due to the limited size, the antennas with strong mutual coupling cannot be used as it affects the efficiency of the antenna and also its correlation. So, implementing MIMO in the design of smartphone antennas is very challenging as in increasing the number of antennas, the isolation between each of them will reduce and this will result in a decrease in their efficiency. Hence achieving high efficiency as well as good isolation in the MIMO antenna is a very critical challenge. So, there is a need to decouple the elements of the antenna to improve the isolation. In [9], an 8-element PIFA-based MIMO antenna system was proposed but it can cover only a single band of $3.5 \mathrm{GHz}$ and the minimum isolation possible between the antenna's elements was $7.4 \mathrm{~dB}$.

Some more research is done that provides good solutions for even $8 \times 8$ MIMO systems [10]-[15]. But these are all for a single band of frequency and hence cannot be used in $5 \mathrm{G}$ communications. $5 \mathrm{G}$ communication needs to address a lot many new applications and needs to meet the new standards of communication. So, it needs multiple frequency ranges. Due to this, it needs multiple antennas that are working in different frequency bands. So, the antennas which can work in multiple bands will be more preferable in smartphones. In this paper, a MIMO antenna consisting of four antennas is proposed. The proposed antenna can work in a dual-frequency range, that is, it not only operates in the frequency range of 3300-3600 MHz but also in the range of (4800-5000) MHz. Again, in this model, the four antennas are along two side edges of the smartphone and hence it can also provide $12 \mathrm{~dB}$ of isolation and can be used in the design of a full-screen smartphone antenna, which can be implemented in the full-screen smartphone.

\section{RESEARCH METHOD}

The design of the MIMO antenna in CST microwave studio [16], [17] for dual-band is divided into the designs of the following subdivisions. In this paper, a MIMO antenna consisting of four antennas is proposed. The proposed antenna can work in a dual-frequency range, that is, it not only operates in the frequency range of 3300-3600 $\mathrm{MHz}$ but also in the range of (4800-5000) $\mathrm{MHz}$.

\subsection{Design of substrate}

The substrate is fabricated first using FR4 substrate [18]. This material has a relative permittivity $\left(\varepsilon_{r}\right)$ of 4.3 and electric loss tangent of 0.025 . Its dimensions are $(130 \times 74 \times 0.8 \mathrm{~mm})$ [19], and it is shown in Figure 1(a).

\subsection{Design of ground on substrate's backside}

The ground is fabricated using copper and is placed at the back of the substrate [20], [21]. Its dimensions are the same as that of the substrate but with a thickness of $0.035 \mathrm{~mm}$, i.e., $(130 \times 74 \times 0.8 \mathrm{~mm})$.

\subsection{Design of side frames of PCB}

One vertical side frame of printed circuit board (PCB) is fabricated first of dimensions, $(0.8 \times 130 \times 4.2 \mathrm{~mm})$. It is then copied to the other side at $74.08 \mathrm{~mm}$ [22]. Then the horizontal side substrate is designed of dimensions $(74 \times 0.8 \times 4.2 \mathrm{~mm})$. This is then copied to the other side at $130.08 \mathrm{~mm}$ [23].

\subsection{Design of front part of antenna on side frames}

The front part of the antenna consists of several bricks, which are designed one after another using copper as material and then are added to give a complete picture as shown in Figure 1(b). The dimensions of each parts are: $(0.035 \times 17.7 \times 1 \mathrm{~mm}) ;(0.035 \times 1.5 \times 1.5 \mathrm{~mm}) ;(0.035 \times 10 \times 0.9 \mathrm{~mm}) ;(0.035 \times 1.5 \times 2.9 \mathrm{~mm})$; $(0.035 \times 16.2 \times 1 \mathrm{~mm})[24]$.

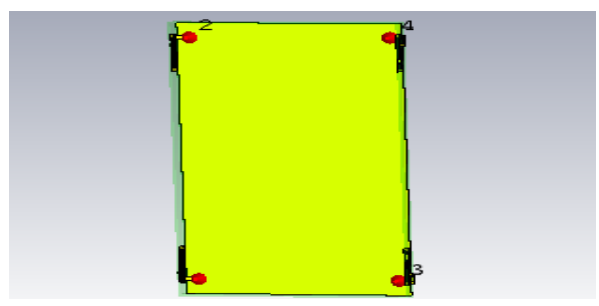

(a)

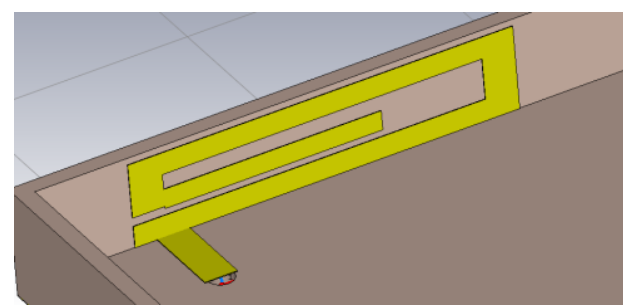

(b)

Figure 1. (a) The main substrate of the antenna and (b) Front view of the antenna 


\subsection{Feeding process}

The bend line in Figure 1(b) shows the feed. Its dimensions are $(4 \times 1.5 \times 0.035 \mathrm{~mm})$. We will use a cylinder for feeding on the main ground whose outer radius is $0.1 \mathrm{~mm}$ [25], [26], and is made of vacuum material as shown in Figure 2(a). The antenna is fed by the main ground.

\subsection{Design of back part of antenna on side frames}

The back part of the antenna consists of 2 bricks, which are designed and then added as shown in Figure 2(b). The dimensions of each part are [27]: $(0.035 \times 1 \times 4.2 \mathrm{~mm})$, and $(0.035 \times 4.4 \times 2 \mathrm{~mm})$.

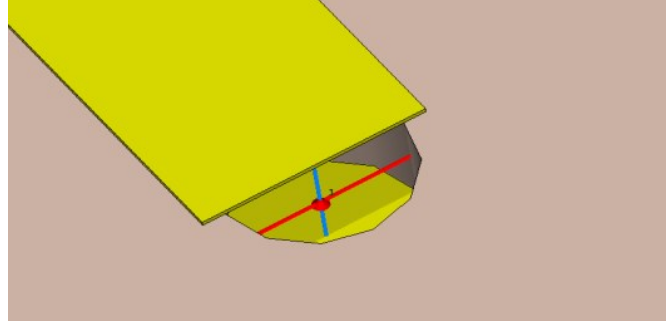

(a)

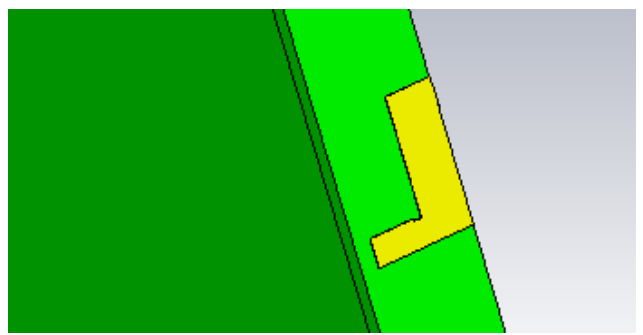

(b)

Figure 2. (a) Feeding part of the antenna and (b) Back part of the antenna

\subsection{Transforming the antenna to the remaining 3 sides and aligning}

After the fabrication of one antenna, it is copied to the other 3 edges of the substrate and is aligned such that the feeding part is facing inside [28], and it is shown in Figure 3. This completes the fabrication. The PCB fabricated is of size $(130 \times 74 \mathrm{~mm})$ which is approximately the same as that of a smartphone of 5 inches. Then the 4 antennas having the same structure and dimensions, $(3.9 \times 17 \mathrm{~mm})$ are fabricated on it such that they are along two side edges of the smartphone and hence the isolation between each of them will be more and their efficiency is not affected.

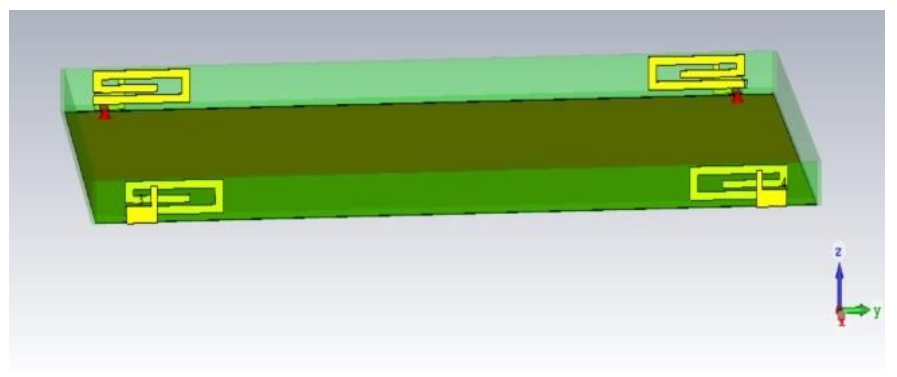

Figure 3. Antenna array structure

\subsection{Start simulation}

After the completion of fabrication, the simulation is done and variations in the parameters like Sparameters, gain and efficiency are observed. The antenna is designed to work in two frequency bands, 3.3 to 3.6 $\mathrm{MHz}$ and 4.8 to $5 \mathrm{MHz}$. The antenna has two parts that are responsible for radiation. The feed part of the monopole with a bent shape as shown in Figure 2 is responsible for radiation from the front part and the L-shaped structure as shown in Figure 2(b) is responsible for radiation from the back part. The capacitance due to coupling between these two radiation parts is mainly responsible for the impedance matching in two frequency bands and hence results in dual-band working [29], [30]. The capacitance generated due to coupling between monopole and the L-shaped structure at back leads to impedance matching at low frequency and hence in the band of 3.3 to $3.6 \mathrm{GHz}$. The length of monopole and feed part resonates around 4.9 $\mathrm{MHz}$ and the capacitance generated due to coupling between feed part and the L-shaped structure at back leads to impedance matching at high frequency and hence in the band of 4.8 to $5 \mathrm{GHz}$. 


\section{RESULTS AND ANALYSIS}

The simulations were carried out using central time zone (CST) microwave studio. The antenna proposed is designed on the side of the PCB to meet the modern technology of smartphones as shown in Figure 3. The S-parameters for the antenna which include both reflection coefficient and transmission coefficient are given in Figure 4. The reflection coefficient of an antenna is desired to have less value because it refers to the power which is reflected without getting transmitted. Similarly, we need to have proper impedance matching so that the signal gets transmitted without any reflection. The reflection coefficients of all four antennas are less than $8 \mathrm{~dB}$ for the given band of frequencies as seen in Figure 4(a), which is as per the requirement. The transmission coefficient at $3.4 \mathrm{GHz}$ is about $-12 \mathrm{~dB}$ and at $4.8 \mathrm{GHz}$ it is less than $-10 \mathrm{~dB}$, which is according to the expected results for smartphone application and can be seen in Figure 4(b).

Voltage standing wave ratio (VSWR) refers to how efficiently the power is transmitted through a transmission line to the load point. If the reflection coefficient and VSWR are less, it indicates that the antenna is matched. Here, the VSWR value is less than 3 as shown in Figure 5 indicating that the antenna is nicely matched and reflection losses are minimized. As all four antennas have the same structure and are simulated under ideal conditions, the VSWR values completely overlap. The antenna efficiency should be as high as possible. Here, the efficiency is around $85 \%$ for the lower band and it is between $(50-60 \%)$ for the higher band of frequency which is shown in Figure 6.

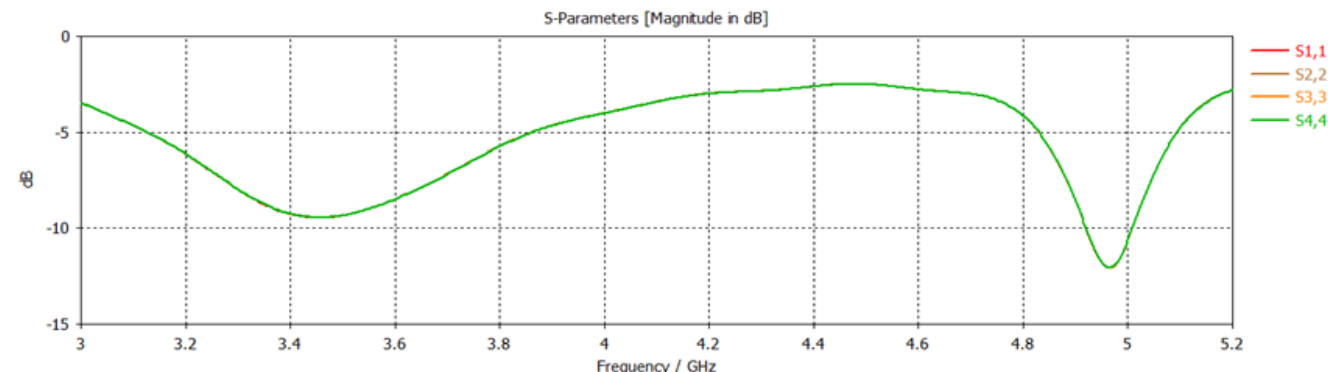

(a)

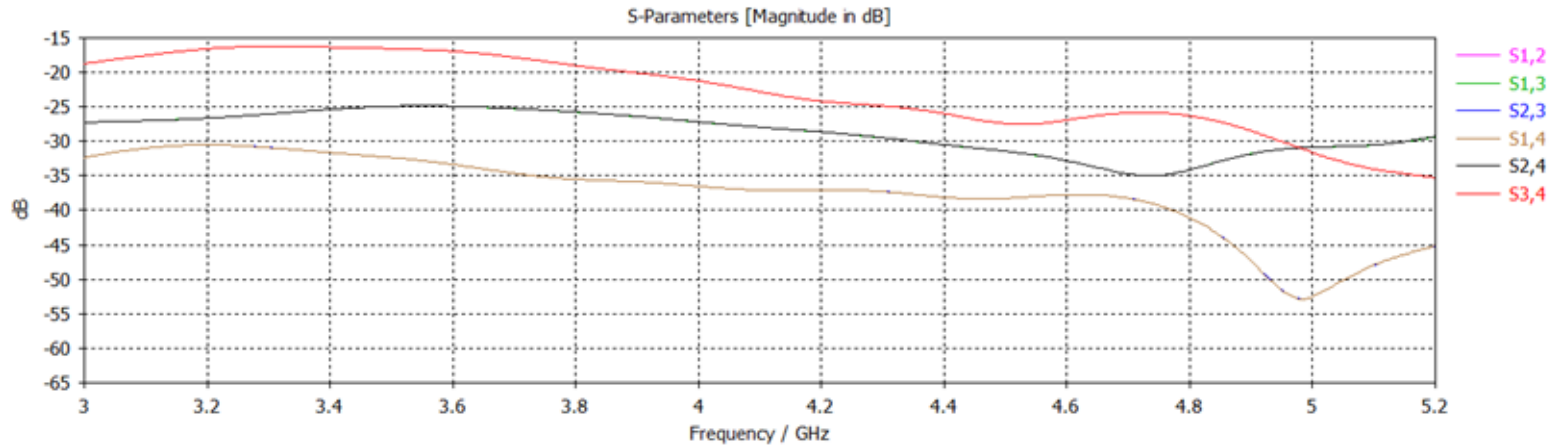

(b)

Figure 4. (a) Reflection coefficient and (b) Transmission coefficient of the simulated antenna

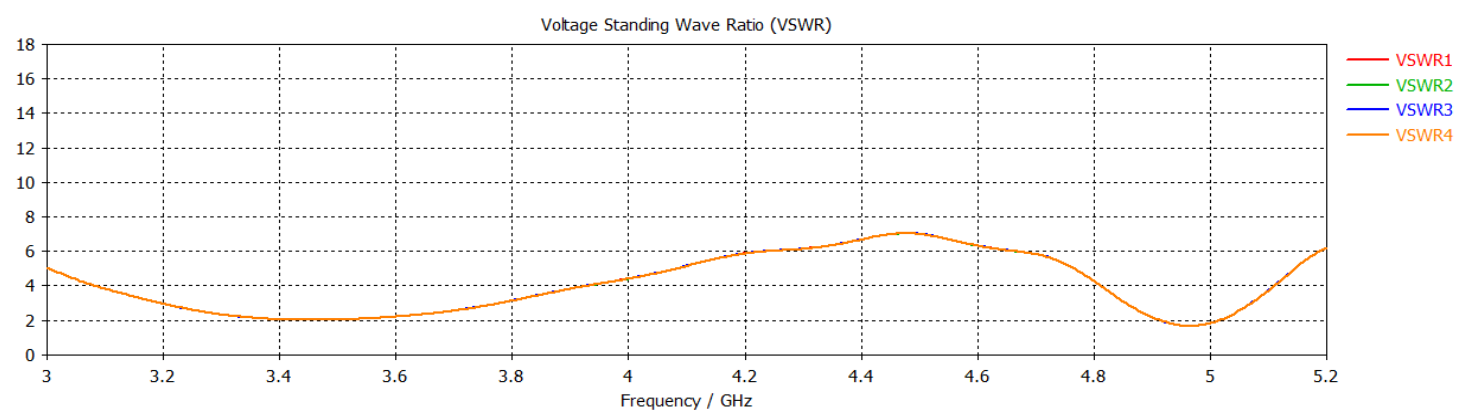

Figure 5. Obtained voltage standing wave ratio (VSWR) 


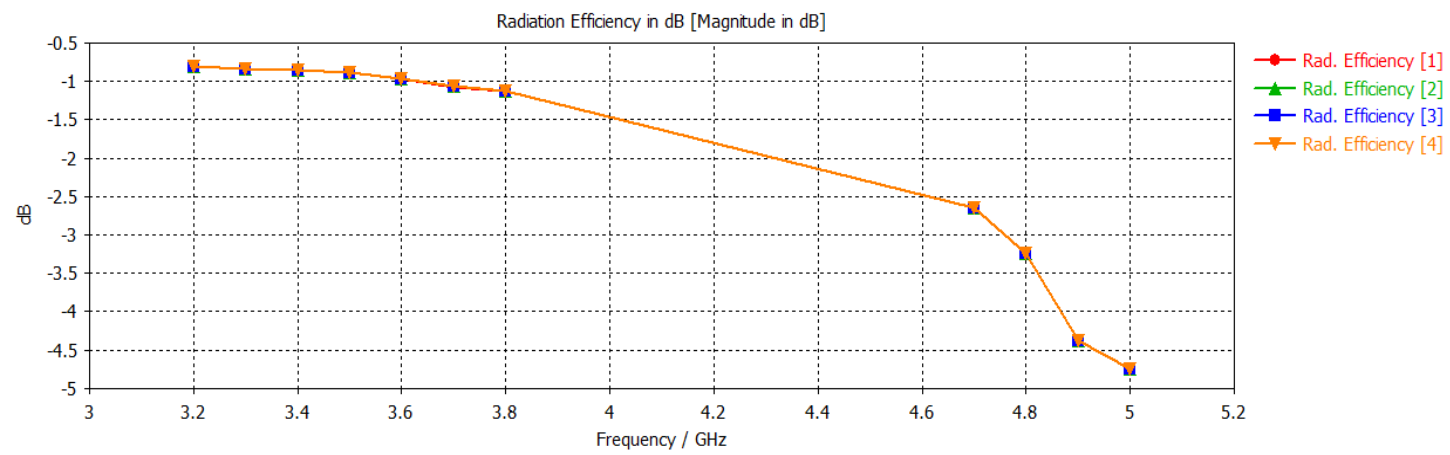

Figure 6. Antenna efficiency

The antenna gain describes how much power is transmitted in the direction of peak radiation to that of an isotropic source. Antenna gain is more commonly quoted than directivity in an antenna's specification sheet because it takes into account the actual losses that occur. The gain should be as high as possible for better power transmission. Here, the gain for the lower frequency band will be around $4 \mathrm{~dB}$ and around $3 \mathrm{~dB}$ for the higher frequency band which is the required gain and can be seen in Figure 7. Figures 7(a) to 7(d) (see Apendix) depicts the farfield gain simulated for $3.4 \mathrm{GHz}$ band, whereas Figures 7(e) to 7(h) (see Apendix).depicts the farfield gain simulated for $4.8 \mathrm{GHz}$ band.

Radiation pattern refers to the way radiated power is varied with respect to the direction away from the antenna. It is the function of the angle of arrival. Hence, the variation in the power radiation is also a function of phi and theta. At phi $=90$, the position of nulls and maxima of all the antennas can be observed from the radiation pattern shown in Figure 8. Directivity measures the pattern of antenna radiation in a specified direction in space In this figure the directivity of all the four antennas in both lower and higher frequency bands has been demonstrated.

Farfield Directivity Abs (Phi=90)

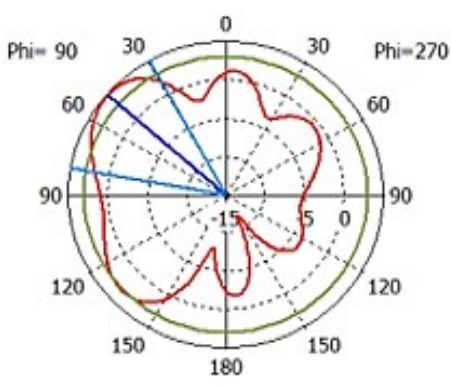

Theta / Degree vs. $\mathrm{dB}$

(a)

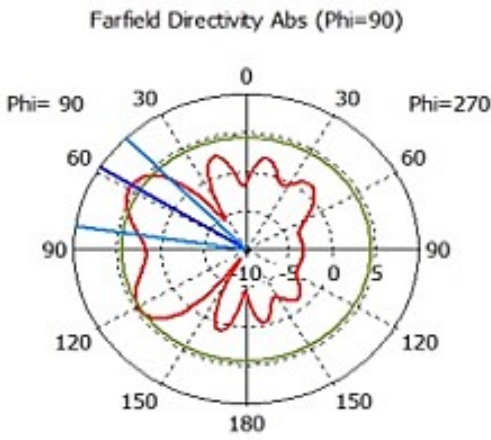

Theta / Degree vs. dBi
Farfield Directivity Abs (Phi $=90$ )

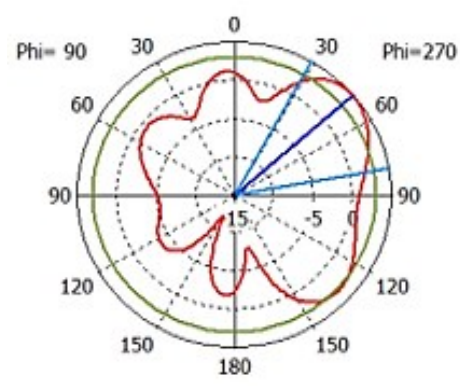

Theta / Degree vs. dBi

Farfield Drectivity Abs (Phi=90)

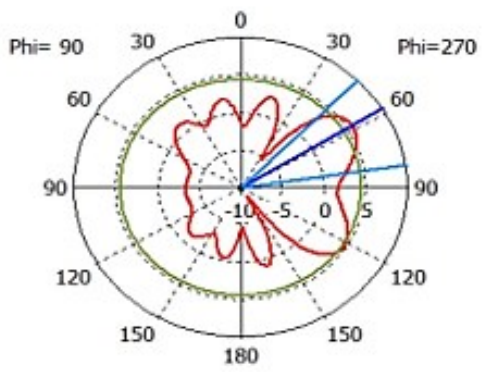

Theta / Degree vs. dBi

(b)

Figure 8. Directivity of (a) $3.4 \mathrm{GHz}$ band in polar form and (b) $4.8 \mathrm{GHz}$ band in polar form 


\section{CONCLUSIONS}

A MIMO antenna with a dual-band feature that can work in both (3.3-3.6) $\mathrm{MHz}$ frequency range and (4.8-5) $\mathrm{MHz}$ frequency range has been designed successfully using CST microwave studio. The proposed antenna has two frequency bands of operation and hence can be used to enhance 5G communication which needs to work in multiple frequency ranges to address a lot many new applications and to meet the new standards of communication. This will also help in providing a stable wireless connection is often difficult to reach locations. Knowing the requirements of $5 \mathrm{G}$ supporting smartphones, this antenna is designed to have a comparatively small size, better impedance matching, less reflection coefficient, more transmission coefficient, more VSWR, and relatively higher isolation. In the near future, one can proceed with a similar type of framework with more number antennas and hence can further increase the data rate and the converging area.

\section{APENDIX}

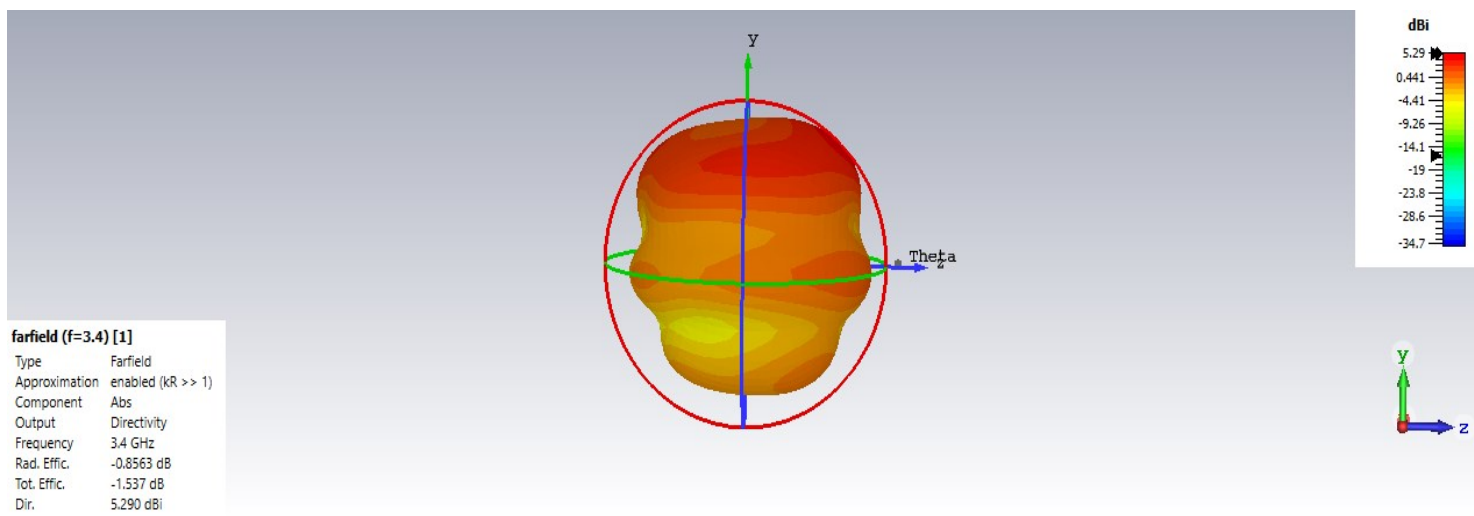

(a)

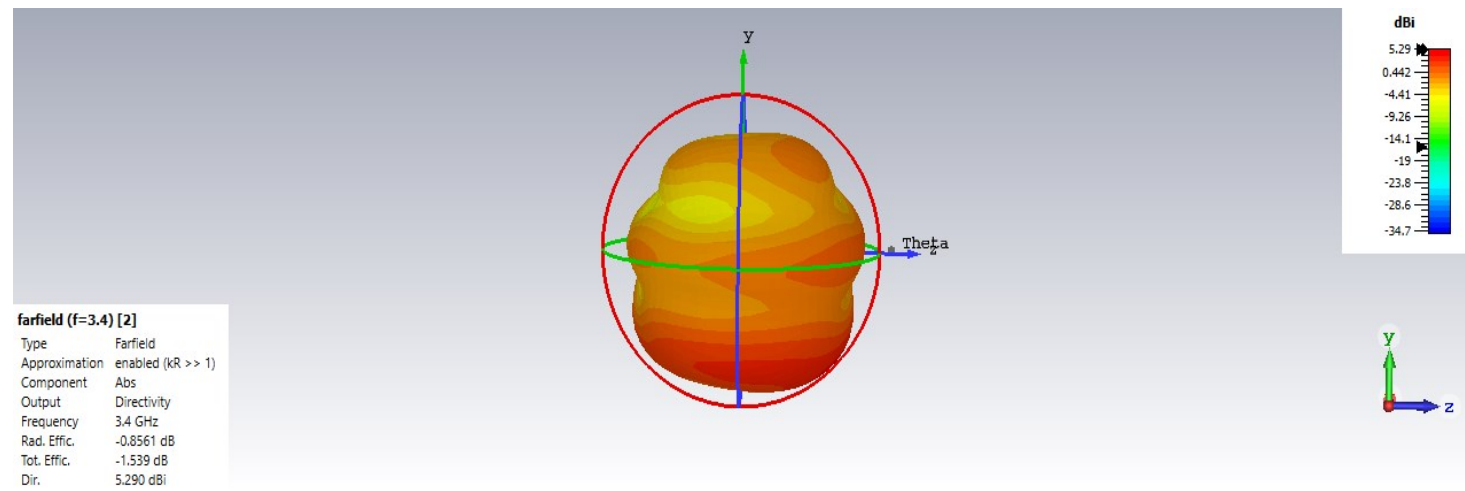

(b)

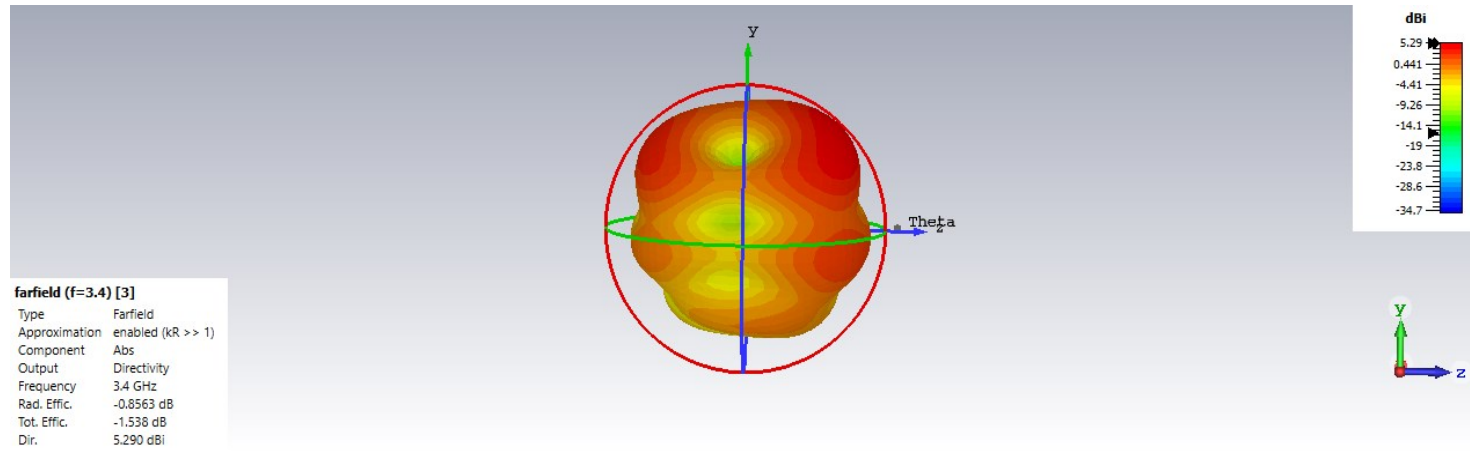

(c)

Figure 7. Farfield gain simulation: (a) for $3.4 \mathrm{GHz}$ band and total efficiency of $-1.537 \mathrm{~dB}$, (b) for $3.4 \mathrm{GHz}$ band and total efficiency of $-1.539 \mathrm{~dB}$, (c) for $3.4 \mathrm{GHz}$ band and total efficiency of $-1.538 \mathrm{~dB}$ 

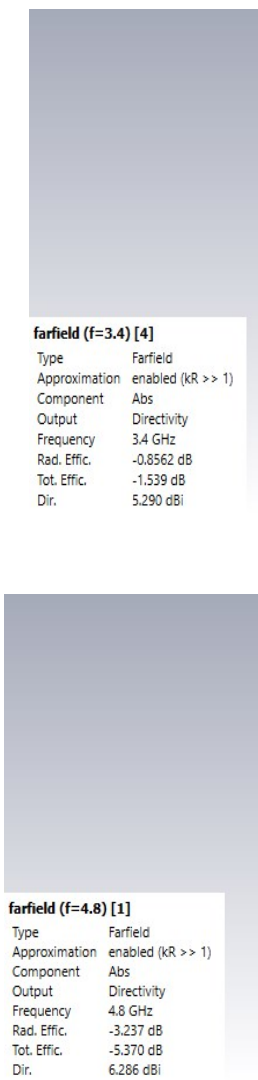

farfield $(f=4.8)[2]$ Type Farfield Component Abs output Directivity Frequency $\quad 4.8 \mathrm{GHz}$ $\begin{array}{ll}\text { Rad. Effic, } & -3.235 \mathrm{~dB} \\ \text { Tot. Effic. } & -5.368 \mathrm{~dB}\end{array}$

farfield $(f=4.8)[3]$ Farfield Approximation enabled (KR >>
Component Tot. Effic., $\quad-5.366 \mathrm{~dB}$ (e) for $4.8 \mathrm{GHz}$ band and total efficiency of $-5.370 \mathrm{~dB}$, (f). for $4.8 \mathrm{GHz}$ band and total efficiency of $-5.368 \mathrm{~dB}$, (g) for $4.8 \mathrm{GHz}$ band and total efficiency of $-5.366 \mathrm{~dB}$ (continue) 


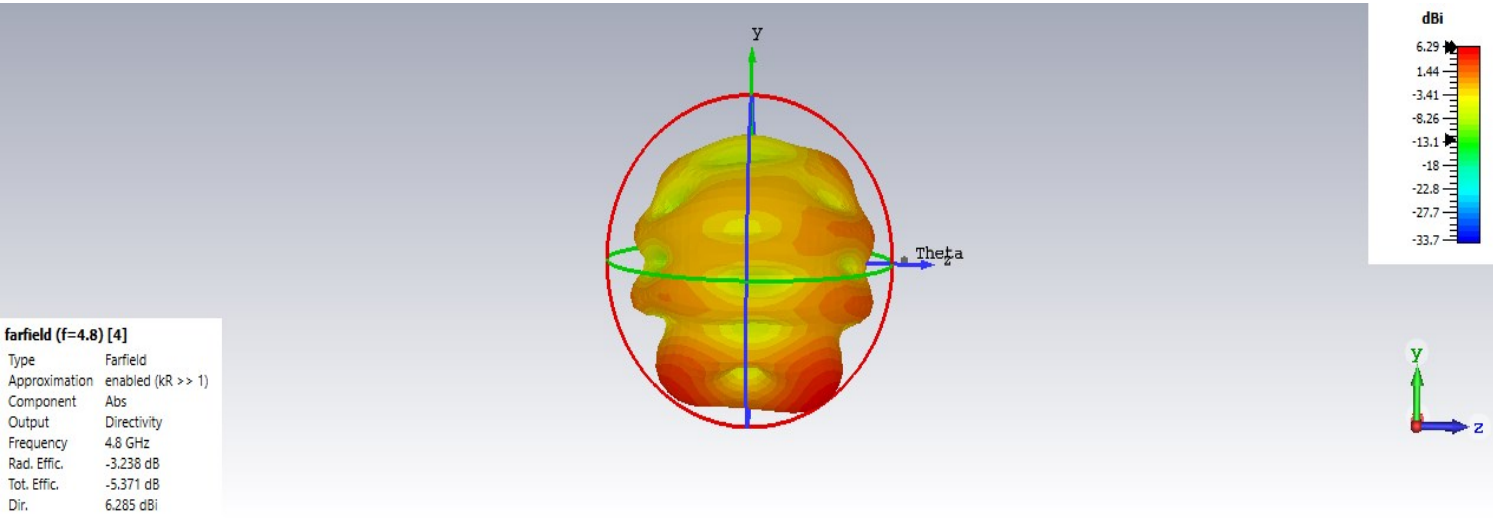

(h)

Figure 7. Farfield gain simulation; (h) for $4.8 \mathrm{GHz}$ band and total efficiency of $-5.371 \mathrm{Db}$ (continue)

\section{ACKNOWLEDGEMENTS}

This research work was funded by "Woosong University’s Academic Research Funding - 2021".

\section{REFERENCES}

[1] J. G. Andrews et al., "What will 5G be?," IEEE Journal on Selected Areas in Communications, vol. 32, no. 6, pp. 1065-1082, Jun. 2014, doi: 10.1109/JSAC.2014.2328098.

[2] C. N. Hu, K. Peng, C. H. Yu, T. W. Hsaio, and D. P. Lin. "Design of a mm-Wave Microstrip Antenna Array," International Workshop on Electromagnetics: Applications and Student Innovation Competition (iWEM), Hsinchu, 2015, pp. 1-2, doi: 10.1109/iWEM.2015.7365030.

[3] A. Salh, L. Audah, N. S. M. Shah, and S. A. Hamzah, "Adaptive Antenna Selection and Power Allocation in Downlink Massive MIMO Systems," Journal of Electrical and Computer Engineering (IJECE), vol. 7, no. 6, pp. 3521-3528, Dec. 2017, doi: 10.11591/ijece.v7i6.pp3521-3528.

[4] Y. L. Ban, Z. X. Chen, Z. Chen, K. Kang, and J. L. W. Li, "Decoupled Closely Spaced Heptaband Antenna Array for WWAN/LTE Smartphone Applications," IEEE Antennas and Wireless Propagation Letters, vol. 13, pp. 31-34, 2014, doi: 10.1109/LAWP.2013.2295623.

[5] Y. L. Ban, C. Li, C. Y. D. Sim, G. Wu, and K. L. Wong, "4G/5G Multiple Antennas for Future Multi-Mode Smartphone Applications," IEEE Access, vol. 4, pp. 2981-2988, 2016, doi: 10.1109/ACCESS.2016.2582786.

[6] Y. Rahayu, J. Wijaya, and E. Syafitri, "Characteristics MIMO 2x4 Antenna for 5G Communication System," TELKOMNIKA (Telecommunication, Computing, Electronics and Control), vol. 16, no. 4, pp. 1508-1514, Aug. 2018, doi: 10.12928/telkomnika.v16i4.8377.

[7] N. I. A. Ishak, N. Seman, and T. H. Chua, "Antenna array design with rectangular ring slot for 5G technology," TELKOMNIKA (Telecommunication, Computing, Electronics and Control), vol. 17, no. 5, pp. 2258-2267, Oct. 2019, doi: 10.12928/telkomnika.v17i5.12816.

[8] K. L. Wong, C. Y. Tsai, and J. Y. Lu, "Two asymmetrically mirrored gap-coupled loop antennas as a compact building block for eight antenna MIMO arrays in the future smartphone," IEEE Transactions on Antennas and Propagation, vol. 65, pp. 1765-1778, Apr. 2017, doi: 10.1109/TAP.2017.2670534.

[9] H. Xu, H. Zhou, S. Gao, H. Wang, and Y. Cheng. "Multimode decoupling technique with independent tuning characteristic for mobile terminals," IEEE Transactions on Antennas and Propagation, vol. 65, pp. 6739-6751, Dec. 2017, doi: 10.1109/TAP.2017.2754445.

[10] A. Zhao and Z. Ren. "Multiple-input and multiple-output antenna system with self-isolated antenna element for fifth generation mobile terminals," Microwave and Optical Technology Letters, vol. 61, pp. 20-27, Jan. 2019, doi: $10.1002 /$ mop.31515.

[11] M. Y. Li et al., "Eight-port orthogonally dual-polarized antenna array for 5G smartphone applications," IEEE Transactions on Antennas and Propagation, vol. 64, pp. 3820-3830, Jun. 2016, doi: 10.1109/TAP.2016.2583501.

[12] T. Firmansyah, S. Praptodiyono, H. D. Aribowo, S. Alam, D. W. Astuti, and M. Yunus, "Bandwidth enhancement and miniaturization of circular - shaped microstrip antenna based on beleved half - cut structure for MIMO $2 \times 2$ application," International Journal of Electrical and Computer Engineering (IJECE), vol. 9, no. 2, pp. 1110-1121, Apr. 2019, doi: 10.11591/ijece.v9i2.pp1110-1121.

[13] T. G. Shivapanchakshari and H. S. Aravinda, "PSO-CCO MIMO - SA: A particle swarm optimization based channel capacity optimization for MIMO system incorporated with smart antenna," International Journal of Electrical and Computer Engineering (IJECE), vol. 10, no. 6, pp. 6276-6282, Dec. 2020, doi: 10.11591/ijece.v10i6.pp6276-6282.

[14] Y. Cui, R. Li, and P. Wang, "Novel Dual-Broadband Planar Antenna and Its Array for 2G/3G/LTE Base Stations," IEEE Transactions on Antennas and Propagation, vol. 61, no. 3, pp. 1132-1139, March 2013, doi: 10.1109/TAP.2012.2229377. 
[15] Y. Li, C. Y. D. Sim, Y. Luo, and G. Yang, "Multi-band 10-antenna array for Sub-6 GHz MIMO applications in 5G smartphones," IEEE Access, vol. 6, pp. 28041-28053, 2018, doi: 10.1109/ACCESS.2018.2838337.

[16] K. L. Wong and J. Y. Lu, "3.6-GHz 10-antenna array for mimo operation in the smartphone," Microw. Opt. Technol. Lett., vol. 57, no. 7, pp. 1699-1704, Jul. 2015, doi: 10.1002/mop.29181.

[17] H. M. R. Nurul, Z. Mansor, and M. K. A. Rahim, "Dual element MIMO planar inverted-F antenna for 5G millimeter wave application," TELKOMNIKA (Telecommunication, Computing, Electronics and Control) vol. 17, no. 4, pp. 1648-1655, Aug. 2019, doi: 10.12928/telkomnika.v17i4.12762.

[18] D. Wu, S. W. Cheung and T. I. Yuk, "A compact and low-profile loop antenna with multiband operation for ultrathin smartphones," IEEE Transactions on Antennas and Propagation, vol. 63, no. 6, pp. 2745-2750, Jun. 2015, doi: 10.1109/TAP.2015.2412962.

[19] Y. L. Ban, Z. X. Chen, Z. Chen, K. Kang, and J. L. W. Li, "Decoupled hepta-band antenna array for WWAN/LTE smartphone applications," IEEE Antennas and Wireless Propagation Letters, vol. 13, pp. 999-1002, 2014, doi: 10.1109/LAWP.2014.2325877.

[20] A. Dkiouak, M. E. Ouahabi, A. Zakriti, M. Khalladi, and A. Mchbal, "Design of a compact hexagonal structured dual band MIMO antenna using orthogonal polarization for WLAN and satellite applications," International Journal of Electrical and Computer Engineering (IJECE), vol. 9, no. 5, pp. 4217-4225, Oct. 2019, doi: 10.11591/ijece.v9i5.pp4217-4225.

[21] P. Sagar and B. Jaymin, "Near Optimal Receive Antenna Selection Scheme for MIMO System under Spatially Correlated Channel," International Journal of Electrical and Computer Engineering (IJECE), vol. 8, no. 5, pp. 3732-3739, Oct. 2018, doi: 10.11591/ijece.v8i5.pp3732-3739.

[22] S. Zhang, A. A. Glazunov, Z. Ying, and S. He, "Reduction of the Envelope Correlation Coefficient with Improved Total Efficiency for Mobile LTE MIMO Antenna Arrays: Mutual Scattering Mode," IEEE Transactions on Antennas and Propagation, vol. 61 no. 6, pp. 3280-3291, Feb. 2013, doi: 10.1109/TAP.2013.2248071.

[23] S. W. Su, C. T. Lee, and F. S. Chang, "Printed MIMO-Antenna System Using Neutralization-Line Technique for Wireless USB Dongle Applications," IEEE Transactions on Antennas and Propagation, vol. 60, no. 2, pp. 456-463, Feb. 2012, doi: 10.1109/TAP.2011.2173450.

[24] Y. Wang and Z. Du, "A Wideband Printed Dual-Antenna System with a Novel Neutralization Line for Mobile Terminals," IEEE Antennas and Wireless Propagation Letters, vol. 12, pp. 1428-1431, Oct. 2013, doi: 10.1109/LAWP.2013.2287199.

[25] K. L. Wong, B. W. Lin, and W. Y. Li. "Dual-band dual inverted/loop antennas as a compact decoupled building block for forming eight 3.5/5.8-GHz MIMO antennas in the future smartphone," Microwave and Optical Technology Letters, vol. 59, pp. 2715-2721, Nov. 2017, doi: 10.1002/mop.30811.

[26] X. Wang, Z. Du, and K. Gong, "A compact wideband planar diversity antenna covering UMTS and $2.4 \mathrm{GHz}$ WLAN bands," IEEE Antennas and Wireless Propagation Letters, vol. 7, pp. 588-591, 2008, doi: 10.1109/LAWP.2008.2000664.

[27] A. Diallo, C. Luxey, P. L. Thuc, R. Staraj, and G. Kossiavas, "Study and reduction of the mutual coupling between two mobile phone PIFAs operating in the DCS1800 and UMTS bands," IEEE Transactions on Antennas and Propagation, vol. 54, no. 11, pp. 3063-3073, Nov. 2006, doi: 10.1109/TAP.2006.883981.

[28] A. Diallo, C. Luxey, P. L. Thuc, R. Staraj, and G. Kossiavas, "Enhanced two-antenna structures for universal mobile telecommunications system diversity terminals," IET Microw. Antennas Propagation, vol. 2, no. 1, pp. 93-101, Feb. 2008, doi: 10.1049/iet-map:20060220.

[29] Y. Rahayu, I. P. Sari, D. I. Ramadhan, and R. Ngah, "High gain 5G MIMO antenna for mobile base station," International Journal of Electrical and Computer Engineering (IJECE), vol. 9, no. 1, pp. 468-476, Feb. 2019, doi: 10.11591/ijece.v9i1.pp468-476.

[30] A. Singal and D. Kedia, "Performance Analysis of Antenna Selection Techniques in MIMO-OFDM System with Hardware Impairments: Energy Efficiency perspective," Journal of Electrical and Computer Engineering (IJECE), vol. 8, no. 4, pp. 2272-2279, Aug. 2018, doi: 10.11591/ijece.v8i4.pp2272-2279. 